\title{
An Acidic PATHOGENESIS-RELATED1 Gene of Oryza grandiglumis is Involved in Disease Resistance Response Against Bacterial Infection
}

\author{
Sang Hyun Shin ${ }^{1}$, Jung-Hun Pak², Mi Jin Kim², Hye Jeong Kim², Ju Sung Oh², Hong Kyu Choi², Ho Won Jung²* \\ and Young Soo Chung ${ }^{2 *}$ \\ ${ }^{1}$ National Crop Experiment Station, Rural Development Administration, Suwon 441-100, Korea \\ ${ }^{2}$ Department of Genetic Engineering, Dong-A University, Busan 604-714, Korea
}

(Received on November 27, 2013; Revised on January 28, 2014; Accepted on February 18, 2014)

Wild rice, Oryza grandiglumis shows hyper-resistance response to pathogen infection. In order to identify genes necessary for defense response in plants, we have carried out a subtractive hybridization coupled with a cDNA macroarray. An acidic PATHOGENESIS-RELATED1 (PRI) gene of the wild rice is highly identical to the acidic $P R 1$ genes of different plant species. The OgPRIa cDNA has an apparent single open reading frame with a predicted molecular mass 40,621 Da and an isoelectic point of 5.14. Both in silico analysis and a transient expression assay in onion epidermal cells revealed that the OgPR1a protein could be localized in intercellular space in plants. The OgPR1a mRNA was strongly transcribed by the exogenous treatment with ethylene and jasmonic acid as well as protein phosphatase inhibitors. Additionally, ectopic expression of the OgPR1a conferred disease resistance on Arabidopsis to the bacterial and fungal infections.

Keywords : acidic PATHOGENESIS-RELATED1 gene, Arabidopsis thaliana, disease resistance, Oryza grandiglumis, Pseudomonas syringae

Plants have unique defense mechanisms to continue their life against adverse environmental conditions since they are sessile living-organisms without any specialized immune cells and circulation system. At the phytopathological point of view, they have acquired effective immune responses in order to protect themselves against pathogen infections.

\footnotetext{
*Co-Corresponding authors.

H.W. Jung

Phone) +82-51-200-7536, FAX) +82-51-200-7505

E-mail)hwjung@dau.ac.kr

Y.S. Chung

Phone) +82-51-200-7510, FAX) +82-51-200-7505

E-mail) chungys@dau.ac.kr
}

Molecular sensing of microbe-associated molecular patterns (MAMPs) by pattern recognition receptor (PRRs) of host plants can initiate relatively weak defense responses, called pattern-triggered immunity (PTI) in plants (Han and Jung, 2013; Jones and Dangl, 2006). As well, plants have another immune receptors, called race-specific resistance (R) proteins to directly or indirectly recognize pathogenderived effector proteins in plant cells (Jones and Dangl, 2006; Spoel and Dong, 2012). Consequently, the R genemediated response restricts the growth of pathogen at the infected regions to prevent successful colonization in plants. The built-in defense responses include the hormonemediated defense responses, the rapid accumulation of callose and reactive oxygen species in infected sites, alternation of transcriptome, and so on (De Vos et al., 2005; Katagiri and Tsuda, 2010; Kawahara et al., 2012). Since Van Loon and Van Kammen (1970) had identified different kinds of pathogenesis-related (PR) proteins in leaves of tobacco plants that exhibited hypersensitive response (HR) to the infection of Tobacco Mosaic Virus (TMV), 17 different kinds of PR proteins were isolated in various plant species (Van Loon et al., 2006).

PR1 proteins are one of well-studied defense-related proteins, even if the molecular function of PR1 protein is not obvious yet (Alexander et al., 1993). Based on the isoelectic point of PR1 proteins, they were classified into two groups as acidic or basic forms (Van Loon and Van Strien, 1999). The basic $P R 1$ genes exhibit approximately $\sim 65 \%$ sequence identities to the acidic PR1 (Cornelissen et al., 1987; Payne et al., 1989). They generally have two discrete signal sequences at $\mathrm{N}$-terminal and C-terminal regions to target extracellular space and vacuole, respectively (Nidermann et al., 1995; Payne et al., 1989; Sessa et al., 1995). These features proposed that the basic PR1 proteins could be dually localized to both regions in plants. Unlike the basic PR1 proteins, acidic PR1 proteins seem to be secreted to the intercellular space in infected leaves 
of plants (Carr et al., 1987; Parent and Asselin, 1984). The acidic PR1 proteins can be sub-divided into three different branches based on sequence identities and their acidity for conferring protein stability in response to acidic $\mathrm{pH}$ in the extracellular space and proteolytic attack (Buchel and Linthorst, 1999). Either acidic or basic PR1 mRNAs were strongly transcribed in leaves of plants exposed to biotic and abiotic stresses, such as pathogen infection, UV-treatments, and wounding (Brederode et al., 1991; Mitsuhara et al., 2008). In addition, exogenous treatment with plant hormones, salicylic acid (SA), jasmonate (JA) and ethylene (ET) also stimulated the strong transcription

A

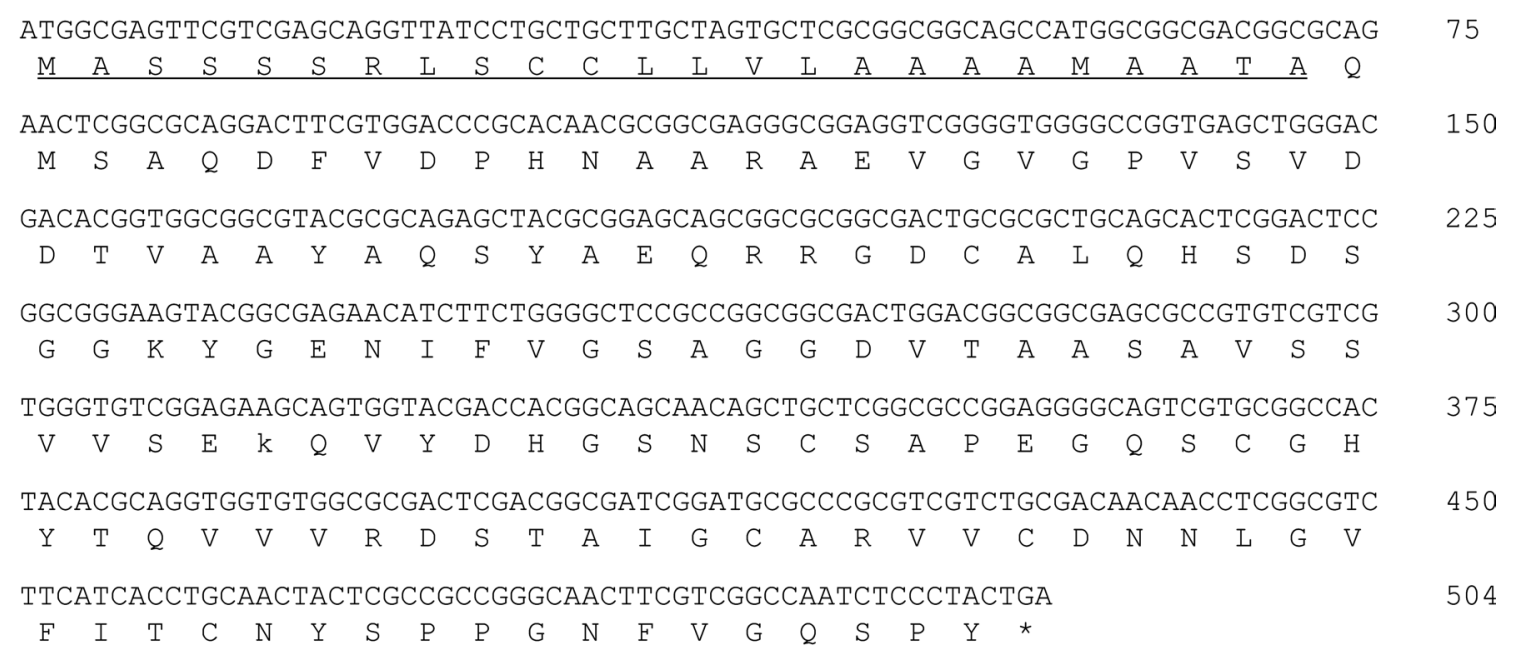

B

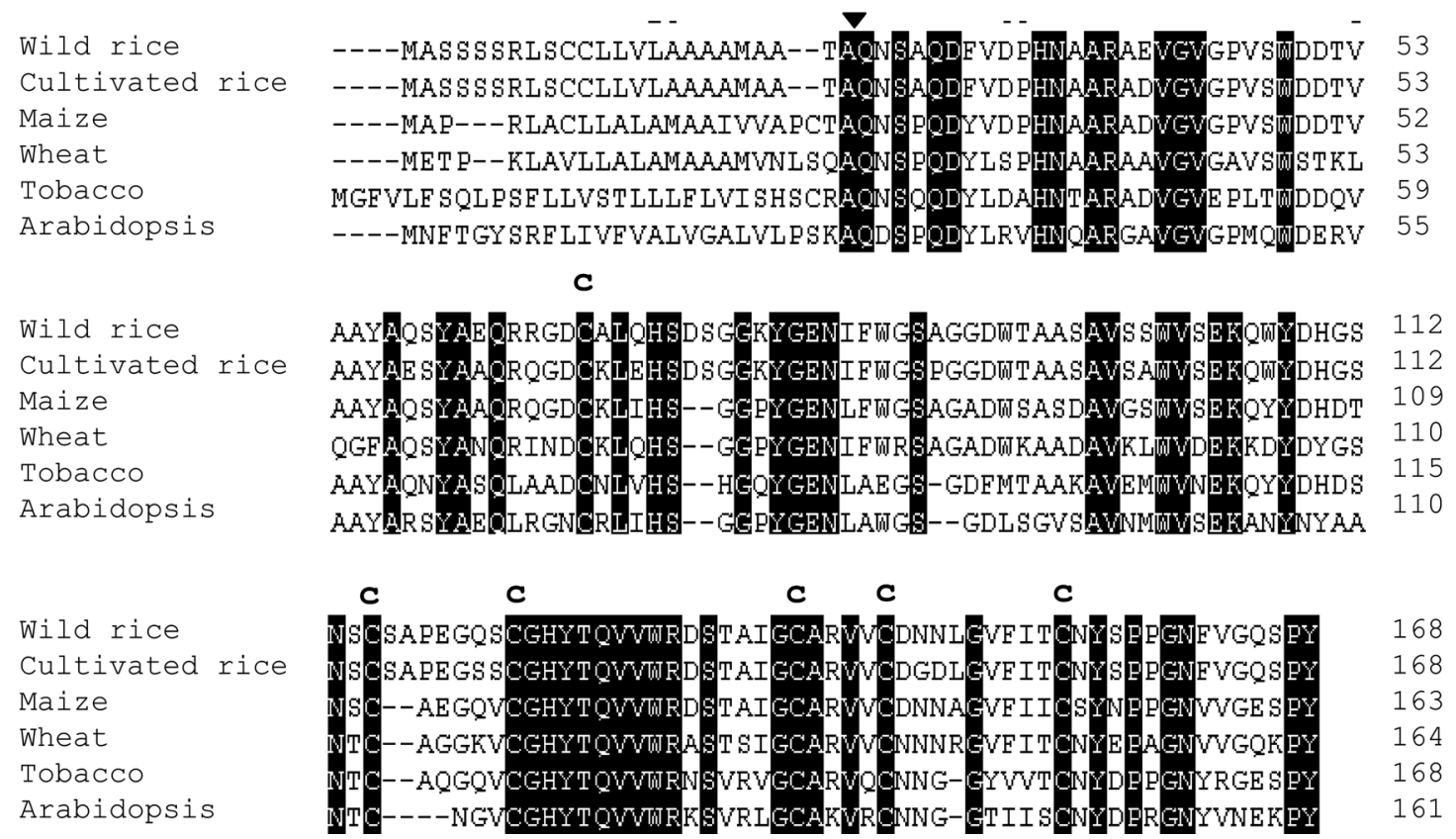

Fig. 1. A typical acidic PATHOGENEGENE-RELATED1 (PRI) gene was identified in leaves of wild rice (Oryza grandiglumis). (A) Nucleotide and deduced amino acid sequence of the OgPRIa gene. The deduced amino acid is designated at the bottom of the sequence. An Asterisk represents the stop codon. The underline indicates the signal peptide sequences. (B) A comparative alignment of the deduced OgPRIa amino acid sequences with its homologous genes of different plant species. Identical amino acid residues are highlighted in black. The arrowhead indicates the cleavage site between the signal peptides and the mature proteins The positions of the cysteine residues for disulphide linkage were shown as Cs. Origin of sequences: rice (AJ278436), maize (U82200), wheat (CAA07473), tobacco (X06930), Arabidopsis (M90508), respectively. 
of PR1 mRNA in plants (Kim and Hwang, 2000; Reymond and Farmer, 1998; Zhang et al., 2010). Thus the level of PR1 mRNA was often used as a molecular marker to predict the establishment of immune response, such as HR and systemic acquired resistance (SAR) (Jung and Hwang, 2000; Jung et al., 2009). It was also known that purified or recombinant PR1 proteins had an anti-oomycete activity against Phytophthora infestans (Niderman et al., 1995). In addition, ectopic expression of $P R 1$ gene enabled the transgenic plants to effectively resist against the pathogen infection, although some reports showed contradictory results (Alexander et al., 1993; Linthorst al., 1989).

Sequence analysis of $O g P R 1 a$ gene. Using SSH (suppression subtractive hybridization) and RACE (rapid amplification of cDNA ends) technology, OgPRIa (an acidic PATHOGENESIS-RELATED1 of O. grandiglumis) cDNA was successfully identified from leaves of wild rice pretreated with wounding and MAMPs (Kim et al., 2005). The EST sequence of OgPRIa gene has been submitted to the GenBank as an accession number CK429151. The OgPRIa cDNA consists of 507 nucleotides with an apparent single open reading frame with a predicted molecular mass 40,621 Da and an isoelectic point of 5.14 (Fig. 1A). The predicted OgPR1a protein has a typical N-terminal hydrophobic signal peptide, which is required to enter into endoplasmic reticulum (Figs. 1A and 1B). The N-terminal signal sequences are completely identical to those of acidic OsPRla gene (Agrawal et al., 2000). Thus we expected that the acidic OgPR1a protein might be secreted to the extracellular space in leaves of wild rice. The deduced amino acid sequences of $O g P R 1 a$ were compared to the previously identified acidic $P R 1$ genes of different plant species (Fig. 1B). Not only did the amino acid sequences of $O g P R 1 a$ have the highest identity to the acidic OSPRla gene of cultivated rice plants $(93.5 \%)$, but also show relatively higher identities to those of monocot plants than dicot plants. Additionally, six cysteine residues important for a proper protein folding were well conserved in the OgPRla protein.

Expression of OgPR1a mRNA by treatment of plant hormones. As mentioned in our previous article, OgPRla mRNA was strongly transcribed in the leaves of wild rice in response to mechanical and chemical stimuli (Kim et al., 2005). Mechanical stresses tended to activate ET- and JAdependent signaling pathway in plants (Díaz et al., 2002; Li et al., 2002). In addition to SA, these two plant hormones, ET and JA also act as main players for regulating defense responses in plants (Denancé et al., 2013). To check if the plant hormones could regulate transcription of $O g P R 1 a$ gene, either ethephon $(1 \mathrm{mM})$, which was converted to ethylene and phosphoric acid, or JA $(100 \mu \mathrm{M})$ was applied on leaf segments of wild rice. The segments were incubated under continuous light condition until harvesting. Total RNAs were isolated from the leaves of wild rice in accordance with the manufacturer's instruction (Invitrogen, Carlsbad, CA). All the procedures for northern hybridization were described elsewhere (Jeon et al., 2012; Shin et al., 2012). The OgPRla mRNA was induced within $24 \mathrm{~h}$ after ethephon treatment and the level of OgPRIa mRNA were gradually increased until $72 \mathrm{~h}$ after treatment (Fig. 2A). Exogenous treatment of JA also stimulated $O g P R l a$ transcription in leaf segments (Fig. 2B). These results indicate that plant hormones can finely tune the level of OgPRIa transcription in response to environmental stimuli, including wounding and pathogen infection. Moreover, the application of two protein phosphatase (PPase) inhibitors, cantharidin $(\mathrm{CN}, 1 \mu \mathrm{M})$ and endothall $(\mathrm{EN}, 1 \mu \mathrm{M})$ also induced the expression of OgPRla mRNA in leaves of wild rice (Fig. 2B). One of possible explanations is that the transcription of OgPRIa might be regulated by hyperphosphorylated certain cellular proteins. It is also plausible that a certain signal transduction pathway regulated by a receptor protein

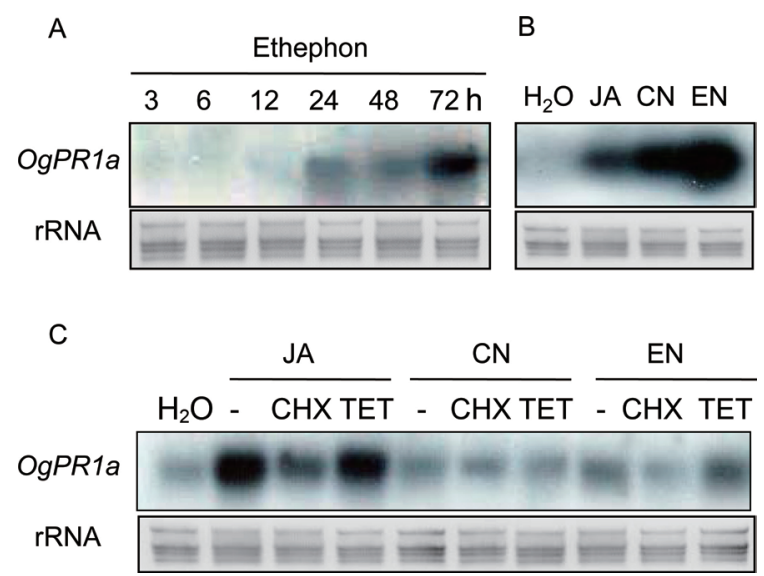

Fig. 2. OgPRla was strongly transcribed in leaves either treated with plant hormones or protein phosphatase inhibitors. (A) Expression of OgPRla gene in leaves of seedling after ethephon treatment. One $\mathrm{mM}$ ethephon was applied on leaves of wild rice, and leaf segments were collected at indicated time points. (B) Exogenous treatment with $100 \mu \mathrm{M}$ of jasmonic acid (JA), $1 \mu \mathrm{M}$ of cantharidin $(\mathrm{CN})$ and $1 \mu \mathrm{M}$ of endothall (EN) also induced OgPRla expression in the leaf segment. (C) Cycloheximide (CHX) inhibited transcription of OgPRla gene. Rice seedlings were treated with $100 \mu \mathrm{M} \mathrm{JA}, 1 \mu \mathrm{M} \mathrm{CN}$ and $1 \mu \mathrm{M}$ EN alone, or together with $10 \mu \mathrm{M} \mathrm{CHX}$ or $10 \mu \mathrm{M}$ tetracycline (TET). $\mathrm{H}_{2} \mathrm{O}$ was used as mock control. As a representative of the equal RNA loading, the ribosomal RNAs in the membrane were stained with methylene blue. 
B

\begin{tabular}{cccccc}
\hline Lines & $\begin{array}{c}\text { Number of } \\
\mathrm{T}_{2} \text { progeny }\end{array}$ & Kan- & Kan+ & df & $\begin{array}{c}\text { Chi- } \\
\text { square }\end{array}$ \\
\hline$\# 6$ & 91 & 18 & 73 & 1 & 1.584 \\
$\# 11$ & 101 & 23 & 78 & 1 & 0.286 \\
$\# 16$ & 51 & 8 & 43 & 1 & 3.41 \\
\hline
\end{tabular}

\section{C}
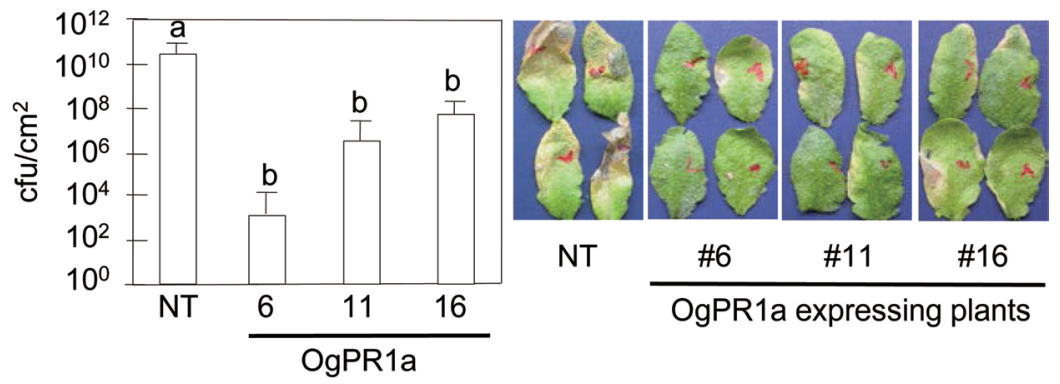

D
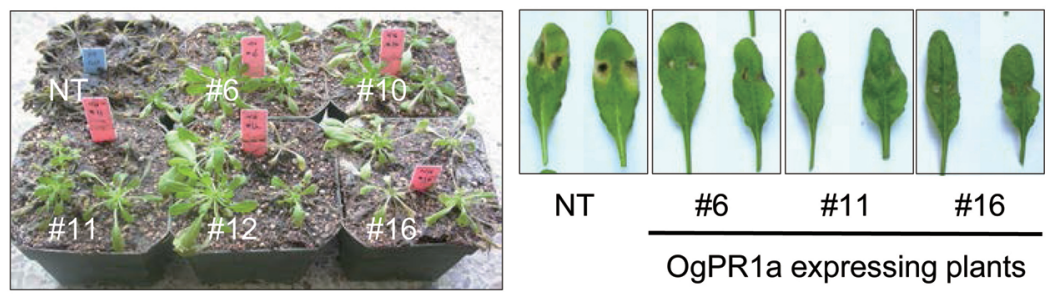

$\mathrm{E}$

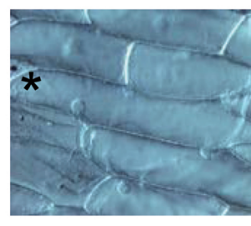

Visible light

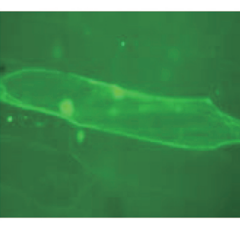

Fluorescence

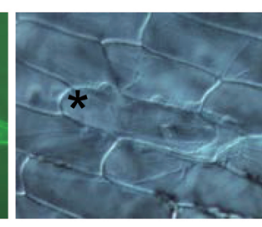

Visible light

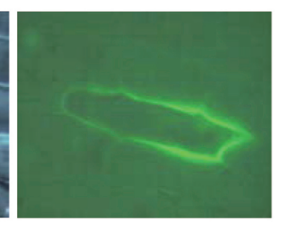

Fluorescence

smGFP

OgPR1a:: smGFP

Fig. 3. Extracellularly localized OgPR1a proteins conferred disease resistance on Arabidopsis plants against bacterial and fungal infection. (A) Ectopic expression of OgPRla gene in Arabidopsis plant. Total RNA was isolated from the non-transgenic (NT) and transgenic plants (line \#1 \#20) and hybridized with the OgPRIa cDNA in order to check whether or not the OgPRIa gene was expressed in leaves of Arabidopsis. Numbers indicate independent lines of transgenic $\mathrm{T}_{1}$ plants. (B) Progeny analysis of $\mathrm{T}_{2}$ Arabidopsis plants. Sterilized seeds of $T_{2}$ generation were sowing on the half strength of MS media containing kanamycin $(100 \mu \mathrm{g} / \mathrm{ml})$, and the number of survived seedling was counted for the analysis. (C) Pseudomonas growth in OgPR1a-expressing plants. P. syringae pv. tomato DC3000 $\left(\mathrm{OD}_{600}=0.0001\right)$ were syringe-infiltrated into leaves of wild-type and OgPR1a-expressing plants. The number of bacteria was monitored on day 3 after inoculation. The photos were also taken 3 days after inoculation. Error bars indicate standard error $(n=5)$. Different letters indicate statistically significant differences $(P<0.01$, student $t$-test). The experiments were repeated twice with similar results. (D) Disease symptoms on wild-type Col-o and transgenic plants on 7 days after spray-inoculation of $B$. cinerea $\left(5 \times 10^{5} \mathrm{conidia} / \mathrm{ml}\right)$ (left panel) and on 4 days after drop-inoculation $\left(5 \times 10^{5}\right.$ conidia/ml) (right panel). (E) Subcellular localization of OgPR1a protein in onion epidermal cells. OgPR1a::smGFP was introduced and transiently expressed in epidermal cells. The pictures were taken under fluorescence microscope (Zeiss). The asterisks point out the cell showing green fluorescene. Note that images of small GFP were duplicated with those described in our previous article because we had monitored OgPR1a-localization together with the OgPR10 proteins (Shin et al., 2012). 
was affected by the exogenous treatment with the PPase inhibitors, because the PPase inhibitors interfered with the activity of protein phosphatase(s) that works together with the receptor protein (Bajsa et al., 2011). Thus the transcription of PRI mRNA seemed to be caused by the aberrant function of receptor protein in plants treated with PPase inhibitors. On the contrary, a PPase inhibitor, okadaic acid effectively suppressed $P R 1$ expression in tobacco plants (Conrath et al., 1997). However, the molecular mechanism of the PPase inhibitors to regulate expression of $P R 1$ gene in plants is still unclear.

Cycloheximide (CHX) and tetracycline (TET) are representative inhibitors of protein synthesis in eukaryotic and prokaryotic cells, respectively. Thus the drugs are used in the biochemical approach to study whether or not de novo protein synthesis was required for any given phenomena. To check an inhibitory efficacy of CHX and TET on $O g$ PRla mRNA expression, $10 \mu \mathrm{M}$ of each compound was supplemented to JA $(100 \mu \mathrm{M}), \mathrm{CN}(1 \mu \mathrm{M})$, and EN (1 $\mu \mathrm{M})$ solutions. Expectedly treatment of CHX effectively hindered the transcription of $O g P R 1 a$ mRNA triggered by treatment with JA, CN and EN (Fig. 2C). These results show the requirement of de novo protein synthesis to induce OgPRIa mRNA expression under biotic or abiotic stress conditions.

OgPR1a-expressing Arabidopsis plants were resistant against bacterial infection. To examine the biological role of $O g P R l a$ gene during pathogenesis and defense response, we have developed OgPR1a-expressing Arabidopsis plants (A. thaliana ecotype Col-0). A full-length cDNA fragment of OgPR $1 a$ was amplified by using gene specific primers (forward primer, 5'-ggatccatggcgagttcgtcgagcagg-3'; reverse primer, 5'-gagctctcagtagggagattggccgac-3') and cloned into BamH1 and SacI sites of the pBI121 binary vector. The resulting construct was introduced into Arabidopsis genome via the floral dipping procedure in order to generate transgenic plants (Clough and Bent, 1998). The putative OgPR1a-expressing transgenic Arabidopsis plants were initially screened on the half strength of MS (Murashige and Skoog) media supplemented with kanamycin at $100 \mu \mathrm{g} / \mathrm{ml}$. Most of kanamycin-resistant $\mathrm{T}_{1}$ generation plants exhibited the stable expression of OgPRla gene in leaves of Arabidopsis plants without any exogenous stimuli (Fig. 3A). Among 20 independent transgenic plants, we have chosen 3 independent transgenic lines (\#6, \#11, and \#16) for further study because of the reasons as following: (1) The OgPR $1 a$ mRNA was strongly expressed in the leaves of Arabidopsis and (2) T-DNA was interposed into a single locus in the Arabidopsis genome (Figs. 3A and 3B).
To monitor disease resistance response of the OgPR1aexpressing plants against pathogen infection, Pseudomonas syringae pv. tomato DC3000 $\left(\mathrm{OD}_{600}=0.0001\right)$ was infiltrated into leaves of 4-week old plants using a needless syringe. We counted the number of bacteria in the leaf discs on 3 days after inoculation. As shown in Fig. 3C, the ectopic expression of OgPR1a effectively inhibited the growth of Pseudomonas in leaves of transgenic Arabidopsis plants, compared to those in wild-type plants. Transgenic tobacco plants carrying a basic PR1 gene of Capsicum annuum $(C a P R 1 b)$ showed enhanced disease resistance response to the infection by Ralstonia solanacearum and P. syringae pv. tabaci (Sarowar et al., 2005). A necrotrophic fungus Botrytis cinerea was also grown on potato dextrose agar under continuous fluorescent light to promote conidial formation. Three-week old wild-type Col-o and OgPR1expressing Arabidopsis were inoculated with the conidial suspension $\left(5 \times 10^{5}\right.$ conidia $\left./ \mathrm{ml}\right)$. The infected plants were kept on a high humidity chamber in order to trigger disease development during 3 days, and transferred in a normal growth chamber (Jung et al., 2008). As shown in figure 3D, symptom development was abolished in OgPR1aexpressing Arabidopsis plants, compared with those seen in wild-type Col-o plants. Our results strongly suggest that PR1 proteins have a certain role to inhibit the bacterial and fungal growth at the infected tissues in plants.

Based on in silico analysis of the deduced amino acid sequences of $O g P R 1 a$ gene (Fig. 1A), we expected that OgPR1a protein would be an extracellular protein in wild rice. To test whether or not the OgPR1a proteins were secreted out of cells in plants, we expressed GFP-fused OgPR1a proteins controlled by CaMV 35S promoter in onion epidermal cells. An OgPRIa open reading frame without a stop codon was amplified with two primers containing $X b a \mathrm{I}$ and $\mathrm{Bam} \mathrm{H} 1$ sites (forward primer, 5'-gggtctagaatggcgagttcgtcgagcagg-3'; reverse primer, 5'-gggggatccgtagggagattggecgacgaa-3'). Finally, the fragments were inserted into XbaI and BamH1 site of the plasmid psmGFP (David and Vierstra, 1996). The OgPRla::smGFP chimeric gene was delivered into onion peels by the particle bombardment experiment (Takeuchi et al., 1992). The green fluorescence was monitored in the epidermal tissues under a fluorescence microscope at $8 \mathrm{~h}$ after incubation on liquid MS media (Axiophot, Zeiss, Germany). As shown in Fig. $3 \mathrm{D}$, green fluorescence was detected in extracellular space, but not in intracellular area in onion epidermal cells. These studies show the possibility that OgPR1a proteins can act as one of anti-microbial compounds in intercellular spaces in plants.

In conclusion, we showed that $O g P R I a$ gene of wild rice 
was involved in disease resistance response in plants. Although a exact biochemical function of the acidic $P R 1$ gene is still unclear during plant defense response, it is likely that the $P R 1$ genes are useful as a genetic source for developing disease resistant crop plants, as well as the molecular marker to monitor defense responses in plants.

\section{Acknowledgements}

This work was supported by the Wu Jang-Choon Project from the Rural Development Administration (RDA) (PJ007850) and Basic Science Research Program from the National Research Foundation of Korea (2010-0006441) to H.W. Jung, and the Next-generation BioGreen21 program from RDA (PJ007978) to Y.S. Chung.

\section{References}

Agrawal, G. K., Jwa, N. S. and Rakwal, R. 2000. A novel rice (Oryza sativa L.) acidic PR1 gene highly responsive to cut, phytohormones, and protein phosphatase inhibitors. Biochem. Biophys. Res. Commun. 274:157-165.

Alexander, D., Goodman, R. M., Gut-Rella, M., Glascock, C., Weymann, K., Friedrich, L., Maddox, D., Ahl-Goy, P., Luntz, T., Ward, E. and Ryals, J. 1993. Increased tolerance to 2 oomycete pathogens in transgenic tobacco expressing pathogenesis-related protein-1a. Proc. Natl. Acad, Sci. USA. 90:7327-7331.

Basja, J., Pan, Z. and Duke, S. O. 2011. Transcriptional responses to cantharidin, a protein phosphatase inhibitor, in Arabidopsis thaliana reveal the involvement of multiple signal transduction pathway. Physiol. Plant. 143:188-205.

Brederode, F. T., Linthorst, H. J. M. and Bol. J. F. 1991. Differential induction of acquired resistance and PR gene expression in tobacco by virus infection, ethephon treatment, UV light and wounding. Plant Mol. Biol. 17:1117-1125.

Buchel, A. S. and Linthorst, H. J. M. 1999. PR1: a group of plant proteins induced upon pathogen infection. In: Pathogenesisrelated proteins in plants, eds. By S. K. Datta and S. Muthukrishnan, pp. 21-47. CRC Press, United States.

Carr, P., Dixon, D. C., Nikolau, B. J., Voelkerding, K. V. and Klessig, D. F. 1987. Synthesis and localization of pathogenesis-related proteins in tobacco. Mol. Cell. Biol. 7:1580-1583.

Clough, S. H. and Bent, A. F. 1998. Floral dip: a simplified method for Agrobacterium-mediated transformation of Arabidopsis thaliana. Plant J. 16:735-743.

Conrath, U., Silva, H. and Klessig, D. F. 1997. Protein dephosphorylation mediates salicylic acid-induced expression of PR-1 genes in tobacco. Plant J. 11:747-757.

Cornelissen, B. J. C., Horowitz, J., Van Kan, J. A. L., Goldberg, R. and Bol. J. F. 1987. Structure of tobacco genes encoding pathogenesis-related proteins from the PR-1 group. Nucleic acids Res. 15:6799-6811.
David, S. J. and Vierstra, R. D. 1996. Soluble derivatives of green fluorescent protein (GFP) for use in Arabidopsis thaliana. Weeds World 3:43-48.

De Vos, M., Van Oosten, V. R., Van Poecke, R. M., Van Pelt, J. A., Pozo, M. J., Mueller, M. J., Buchala, A. J., Metraux, J. P., Van Loon, L. C., Dicke, M. and Pieterse, C. M. 2005. Signal signature and transcriptome changes of Arabidopsis during pathogen and insect attack. Mol. Plant-Microbe Interact. 18:923-937.

Denancé, N., Sánchez-Vallet, A., Goffner, D. and Molina, A. 2013. Disease resistance or growth: the role of plant hormones in balancing immune responses and fitness costs. Front. Plant Sci. 4:155.

Díaz, J., ten Have, A. and Van Kan, J. A. L. 2002. The role of ethylene and wound signaling in resistance of tomato to Botrytis cinerea. Plant Physiol. 129:1341-1351.

Han, S. W. and Jung, H. W. 2013. Molecular sensors for plant immunity; pattern recognition receptors and race-specific resistance proteins. J. Plant Biol. 56:357-366.

Jeon, E. H., Pak, J. H., Kim, M. J., Kim, H. J., Shin, S. H., Lee, J. H., Kim, D. H., Oh, J. S., Oh, B. J., Jung, H. W. and Chung, Y. S. 2012. Ectopic expression of ubiquitin-conjugating enzyme gene from wild rice, $O g U B C 1$, confers resistance against UV-B radiation and Botrytis infection in Arabidopsis thaliana. Biochem. Biophys. Res. Commun. 427:309-314.

Jones, J. D. G. and Dangl, J. L. 2006. The plant immune system. Nature 444:323-329.

Jung, H. W. and Hwang, B. K. 2000. Isolation, partial sequencing, and expression of pathogenesis-related cDNA genes from pepper leaves infected by Xanthomonas campestris pv. vesicatoria. Mol. Plant-Microbe Interact. 13:136-142.

Jung, H. W., Lim, C. W., Lee, S. C., Choi, H. W., Hwang, C. H. and Hwang, B. K. 2008. Distinct roles of the pepper hypersensitive induced reaction protein gene CaHIRl in disease and osmotic stress, as determined by comparative transcriptome and proteome analyses. Planta 227:409-425.

Jung, H. W., Tschaplinski, T. J., Wang, L., Glazebrook, J. and Greenberg, J. T. 2009. Priming in systemic plant immunity. Science 324:89-91.

Katagiri, F. and Tsuda, K. 2010. Understanding the plant immune system. Mol. Plant-Microbe Interact. 23:1531-1536.

Kawahara, Y., Oono, Y., Kanamori, H., Matsumoto, T., Itoh, T. and Minami, E. 2012. Simultaneous RNA-Seq analysis of a mixed transcriptome of rice and blast fungus interaction. PLoS ONE 7:e49423.

Kim, K. M., Cho, S. K., Shin, S. H., Kim, G. T., Lee, J. H., Oh, B. J., Kang, K. H., Hong, J. C., Choi, J. Y., Shin, J. S. and Chung, Y. S. 2005. Analysis of differentially expressed transcripts of fungal elicitor- and wound-treated wild rice (Oryza grandiglumis). J. Plant Res. 118:347-354.

Kim, Y. J. and Hwang, B. K. 2000. Pepper gene encoding a basic pathogenesis-related 1 protein is pathogen and ethylene inducible. Physiol. Plant. 108:51-60.

Li, L., Li, C., Lee, G. I. and Howe, G. A. 2002. Distinct roles for jasmonate synthesis and action in the systemic wound re- 
sponse of tomato. Proc. Natl. Acad. Sci. USA. 99:6416-6421. Linthorst, H. J., Meuwissen, R. L., Kauffmann, S. and Bol. J. F. 1989. Constitutive expression of pathogenesis-related proteins PR1, GRP, and PR-5 in tobacco has no effect on virus infection. Plant Cell 1:285-291.

Mitsuhara, I., Iwai, T., Seo, S., Yanagawa, Y., Kawahigasi, H., Hirose, S., Ohkawa, Y. and Ohashi, Y. 2008. Characteristic expression of twelve rice PR1 family genes in response to pathogen infection, wounding, and defense-related signal compounds (121/180). Mol. Genet. Genomics 279:415-427.

Niderman, T., Genetet, I., Bruyère, T., Gees, R., Stinzi, A., Legrand, M., Fritig, B. and Mösinger, E. 1995. Pathogenesis-related PR1-proteins are antifungal. Isolation and characterization of three 14 kilodalton proteins of tomato and of a basic PR-1 of tobacco with inhibitory activity against Phytophthora infestans. Plant Physiol. 108:17-27.

Parent, J. G. and Asselin, A. 1984. Detection of pathogenesisrelated proteins (PR or b) and of other proteins in the intercellular fluid of hypersensitive plants infected with Tobacco mosaic virus. Can. J. Bot. 52:564-569.

Payne, G., Middlesteadt, W., Desai, N., Williams, S., Dincher, S., Carnes, J. and Ryals, J. 1989. Isolation and sequence of a genomic clone encoding the basic form of pathogenesis-related protein 1 from Nicotiana tabacum. Plant Mol. Biol. 12:595596.

Reymond, P. and Farmer, E. E. 1998. Jasmonate and salicylate as global signals for defense gene expression. Curr. Opin. Plant Biol. 1:404-411.

Sarowar, S., Kim, Y. J., Kim, W. N., Kim, K. D., Hwagn, B. K., Islam, R. and Shin, J. S. 2005. Overexpression of a pepper basic pathogenesis-related 1 gene in tobacco plants enhances resistance to heavy metal and pathogen stresses. Plant Cell
Rep. 24:216-224.

Sessa, G., Yang, X. Q., Raz, V., Eyal, Y. and Fluhr, R. 1995. Darkinduction and subcellular localization of the pathogenesisrelated PRB-1b protein. Plant Mol. Biol. 28:537-547.

Shin, S. H., Pak, J. H., Kim, M. J., Kim, H. J., Lee, J. H., Kim, D. H., Choi, H. K., Kang, K. H., Jeong, J. U., Kang, C. S., Jung H. W. and Chung, Y. S. 2012. Cloning and characterization of pathogenesis-related gene $10 \mathrm{a}(\mathrm{Og} P R 10 a)$ derived from wild rice (Oryza grandiglumis). Kor. J. Breed. Sci. 44:1-10.

Spoel, S. H. and Dong, X. 2012. How do plants achieve immunity? Defense without specialized immune cells. Nat. Rev. Immun. 12:89-100.

Takeuchi, Y., Dotson, M. and Keen, N. T. 1992. Plant transformation: a simple particle bombardment device based on flowing helium. Plant Mol. Biol. 18:835-839.

Van Loon, L. C. and Van Kammen, A. 1970. Polyacrylamide disc electrophoresis of the soluble leaf proteins from Nicotiana tabacum var. 'Samsun' and 'Samsun NN'. II. Changes in protein constitution after infection with Tobacco mosaic virus. Virology 40:199-211.

Van Loon, L. C. and Van Strien, E. A. 1999. The families of pathogenesis-related proteins, their activities, and comparative analysis of PR-1 type proteins. Physiol. Mol. Plant Pathol. 55:85-97.

Van Loon, L. C., Rep, M. and Pieterse, C. M. 2006. Significance of inducible defense-related proteins in infected plants. Annu. Rev. Phytopathol. 44:135-162.

Zhang, J., Du, X., Wang, Q., Chen, X., Lv, D., Xu, K., Qu, S. and Zhang, Z. 2010. Expression of pathogenesis related genes in response to salicylic acid, methyl jasmonate and 1aminocyclopropane-1 carboxylic acid in Malus hupehensis (Pamp.) Rehd. BMC Res. Notes 3:208. 